\title{
Meta Analysis the Effect of Gestational Diabetes Mellitus on Macrosomia and Sectio Caesarea
}

\author{
Tantri Yunita Ratna'), Yulia Lanti Retno Dewi²), Bhisma Murti1) \\ 1)Masters Program in Public Health,Universitas Sebelas Maret \\ ${ }^{2)}$ Faculty of Medicine, Universitas Sebelas Maret
}

\section{ABSTRACT}

Background: Gestational Diabetes Mellitus (GDM) is the degree of glucose intolerance that occurs during pregnancy. DMG is caused by damage to cells and insulin resistance, resulting in hyperglycemia and an increase in abnormal growth/macrosomia which causes cesarean delivery. This study aims to analyze the magnitude of the effect of DMG on the incidence of macrosomia and caesarean section with a metaanalysis study.

Subjects and Method: This research is a systematic review and meta-analysis conducted using PRISMA flow diagram. Article searches were conducted through journal databases including: PubMed, Science Direct, and Google Scholar by selecting articles published in 20002020. The keywords used were: "gestational diabetes mellitus" OR "diabetes in pregnancy" AND macrosomiaAND "sectio caesarean" OR "perinatal outcomes" OR "pregnancy outcome". The inclusion criteria in this study were full text articles with an observational study design, articles using English, analysis using multivariate with adjusted odds ratio. Eligible articles were analyzed using Revman 5.3 app.
Results: A total of 22 articles were reviewed in this study with a cohort study design. Metaanalysis of 12 articles showed that pregnant women with gestational diabetes mellitus had a 1.36 times risk of giving birth to a macrosomic baby compared to those without gestational diabetes mellitus (aOR=1.36; 95\% $\mathrm{CI}=1.15$ to $1.60 ; \mathrm{p}<0.003$ ), while 10 articles showed pregnant women with gestational diabetes mellitus had a 1.35 times risk for cesarean delivery than those without gestational diabetes mellitus $(\mathrm{aOR}=1.35 ; 95 \% \mathrm{CI}=1.17$ to $1.55 ; \mathrm{p}<0.001)$.

Conclusion: Gestational Diabetes Mellitus has a weak effect on macrosomia births and caesarean section.

Keywords: gestational diabetes mellitus, macrosomia, sectio caesarean, meta analysis

\section{Correspondence:}

Tantri Yunita Ratna. Masters Program in Public Health, Universitas Sebelas Maret. Jl. Ir. Sutami 36A, Surakarta 57126, Central Java. Email: tantriyunita66@gmail.com. Mobile: 082338868869.

Cite this as:

Ratna TY, Dewi YLR, Murti B (2021). Meta Analysis the Effect of Gestational Diabetes Mellitus on Macrosomia and Sectio Caesarea. 06(o3): 376-387. https://doi.org/10.26911/thejmch.2021.06.03.12.

\section{BACKGROUND}

Gestational Diabetes Mellitus (GDM) is the degree of glucose intolerance that occurs for the first time in pregnancy. GDM occurs due to insufficient insulin secretion in the pancreas during a state of insulin resistance caused by pregnancy. Insulin resistance appears in pregnancy as a result of the secretion of hormones such as progesterone, growth hormone, corticotropin- releasing hormone and placental lactogen. These hormones encourage metabolic changes and make the fetus receive adequate nutrition (Glastras, 2012).

In Indonesia, the prevalence of GDM (according to O'Sullivan's diagnostic criteria) is $1.9-3.6 \%$. In a cohort study $40-60 \%$ of this group will develop type 2 diabetes (DMT2) or impaired glucose tolerance (IGT). In a prospective study in Makassar 
among 46 women with GDM, the incidence of T2DM and impaired glucose tolerance (IGT) after 6 years of delivery was 56.6\% (Purnamasari et al., 2013). There are several differences in the prevalence rate of DMG in Northern Europe, such as the Netherlands at $0.6 \%$, Denmark at 3.6\% and higher in Italy at $6.3 \%$, while in the United States it is 7\% (Baz et al., 2016), while in China, The prevalence of GDM is around 17.5\%. DMG is caused by insulin resistance or reduced insulin action due to hormone production by the placenta, other risks also include old age of pregnant women, obesity and so on (Zhou et al., 2020).

Several studies have shown that GDM can increase the risk of adverse pregnancy outcomes such as the occurrence of macrosomia, caesarean section, neonatal hypoglycemia, respiratory distress syndrome and fetal death (Jiang et al., 2019). But there are also some women who have DMG can give birth to healthy babies by controlling blood glucose levels well such as a diabetic diet, exercise and maintaining weight (Gasim, 2012).

One of the adverse perinatal outcomes of GDM is macrosomia. Macrosomia is defined as a birth weight of 4000 grams or more (Groof et al., 2019). Macrosomia is caused by the mother experiencing hyperglycemia which can cause the fetus to become hyperinsulinemic and hyperglycemic, resulting in excessive use of glucose and causing abnormal growth in the fetus (Catalano et al., 2011). Globally, macrosomia affects $3 \%-15 \%$ of all pregnancies. In developed countries, the incidence of macrosomia ranges from $5 \%-20 \%$ of all births. Fetal macrosomia also complicates the delivery process for both the mother and the newborn (Biratu et al., 2018).

In addition to perinatal, there are also adverse pregnancy outcomes from GDM in the mother, one of which is cesarean deli- very. In pregnant women who have diabetes mellitus, the overall caesarean section rate is $35.1 \%$, compared to $1.52 \%$ for pregnant women without diabetes mellitus. Diabetes mellitus is also a risk factor for wound infection after cesarean section surgery (Wang et al., 2019).

Several studies have been conducted to determine and estimate the effect of gestational diabetes mellitus on the incidence of macrosomia birth and caesarean section, including those conducted by Groof et al., (2019) which showed that GDM has a risk of 2.36 times having macrosomia birth and 1.76 times having a cesarean section than not having GDM. Reinders et al., (2020) also stated that there was a relationship between DMG, where the risk of experiencing macrosomia births was 1.13 times and caesarean section 1.70 times. According to Hossein-nezhad et al., (2007), DMG has a 9.58 times risk of experiencing macrosomia births when compared to women without DMG. According to ( $\mathrm{Su}$ et al., 2019), women who suffer from DMG are at risk of 1.59 times experiencing macrosomia births and 1.18 times having cesarean section. According to (Muche et al., 2020), states that DMG have a 3.81 times risk of experiencing macrosomia births compared to women without DMG.

Based on the high incidence of macrosomia and cesarean section in DMG women, this is due to the high content of hyperinsulin in the fetus and an increase in abnormal growth so that appropriate prevention and treatment are needed. The data that has been obtained by the researchers will then be analyzed with a meta-analysis study design. Meta-analysis is an epidemiological study that provides the strongest evidence for causality by combining and statistically combining the results from a number of independent primary studies where possible. In the meta-analysis, the 
researcher also tested the same hypothesis, in the same way so that a quantitative overview was obtained (Murti, 2018). The results will be analyzed using RevMan 5.3 software, which has previously been synthesized to reduce bias.

\section{SUBJECTS AND METHOD}

\section{Study Design}

The study design used in this study was a systematic review and meta-analysis, using the PRISMA diagram flow guidelines. Article searches were conducted using journal databases including: PubMed, Google Scholar and Science Direct. The keywords used were: "gestational diabetes mellitus" OR "diabetes in pregnancy" AND macrosomia AND "sectio caesarean" OR "perinatal outcomes" OR "pregnancy outcome".

\section{Inclusion Criteria}

The inclusion criteria were full-text papers using observational methods (cohort study design), multivariate analysis with adjusted odds ratio, intervention in the form of gestational diabetes mellitus, research subjects were pregnant women and outcomes were macrosomia births and caesarean sections.

\section{Exclusion Criteria}

Articles published before 2000 and articles published in languages other than English.

\section{Operational Definition}

In formulating the problem of this study, the writer applied PICO formula (Population, Intervention, Comparison and Outcome). The PICO in this study is Population, namely all pregnant women. .
Gestational Diabetes Mellitus is the degree of glucose intolerance that occurs during pregnancy.

Macrosomia is a neonatal birth weight of 4,000 grams.

Sectio Caesar is delivery of the fetus through a surgical incision made through the abdominal wall (laparotomy) and the uterine wall (hysterotomy).

\section{Study Instrument}

An assessment of the quality of research articles was carried out using the Critical Appraisal Checklist for Cohorts (CEBMa, 2014).

\section{Data Analysis}

The Review Manager application (RevMen 5.3) was used in analyzing the data in this study. The results of data analysis are in the form of effect size values and study heterogeneity which later the results of the data that have been analyzed are interpreted in the form of forest plots and funnel plots.

\section{RESULTS}

Research from primary studies related to the effect of Gestational Diabetes Mellitus on macrosomia births and cesarean delivery consisted of 22 studies originating from 6 studies from the Asian continent, 3 studies from the North American continent, 3 European continents and 1 Australian continent. Figure 1 shows the total articles obtained, namely as many as 22 articles from PubMed, Google Scholar and Science Direct. The search for articles was carried out using a database based on PRISMA flow diagrams. 
Ratna et al./ Effect of Gestational Diabetes Mellitus on Macrosomia and Sectio Caesarea

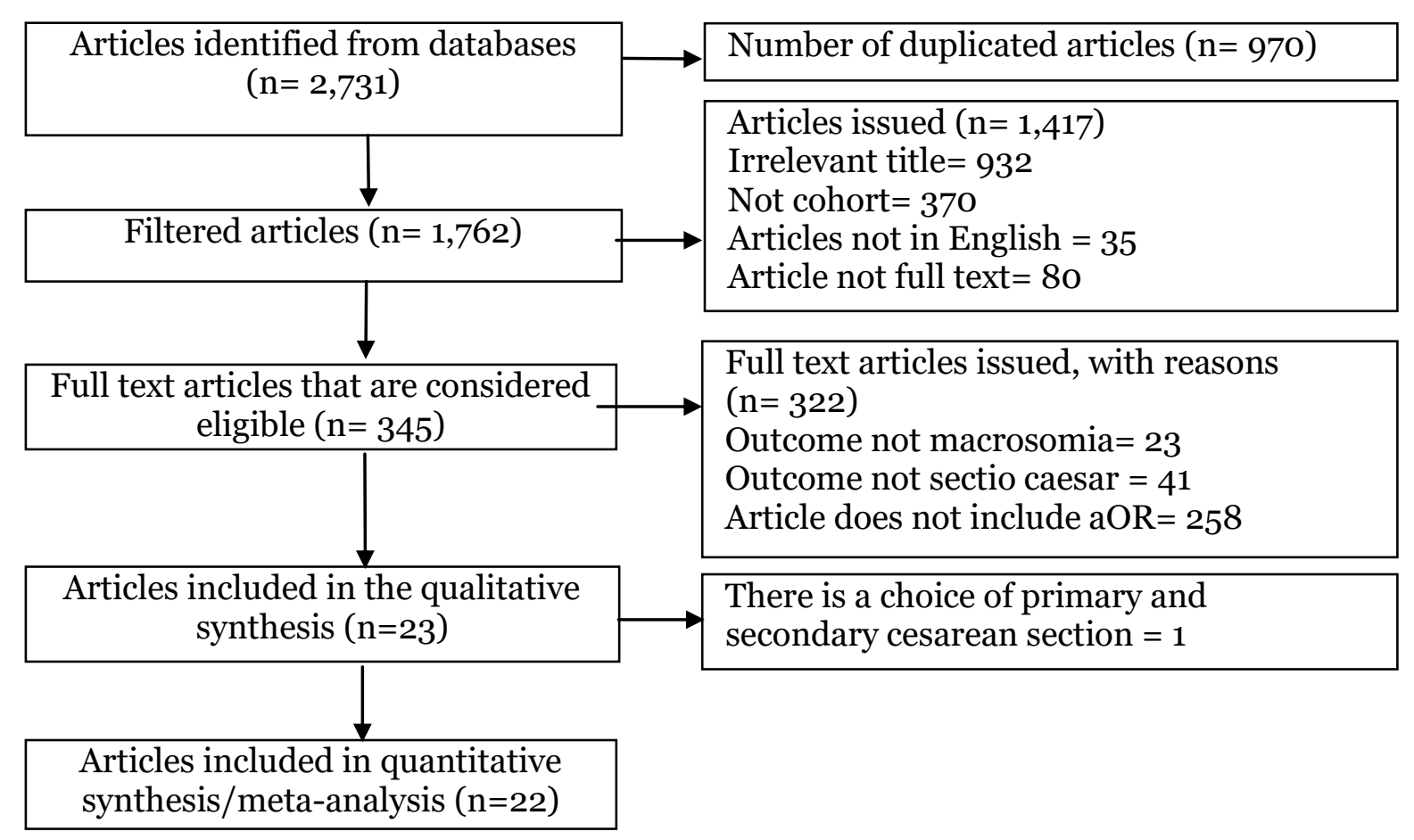

Figure 1. PRISMA flow chart

\section{Effect of gestational diabetes mellitus on macrosomia birth}

\section{a. Forest Plot}

\begin{tabular}{|c|c|c|c|c|c|c|c|c|}
\hline Study or Subgroup & log[Odds Ratio] & $\mathrm{SE}$ & \multicolumn{2}{|r|}{ Odds Ratio } & \multicolumn{4}{|c|}{$\begin{array}{c}\text { Odds Ratio } \\
\text { IV, Random, } 95 \% \mathrm{Cl}\end{array}$} \\
\hline Fadl 2010 & 0.4886 & 0.0424 & $11.9 \%$ & $1.63[1.50,1.77]$ & & & - & \\
\hline Gasim 2012 & 0.9821 & 0.3946 & $3.3 \%$ & $2.67[1.23,5.79]$ & & & & \\
\hline Jiang 2018 & 0.3436 & 0.2892 & $5.0 \%$ & $1.41[0.80,2.49]$ & & & - & \\
\hline Kgosidialwa 2015 & -0.734 & 0.1328 & $9.4 \%$ & $0.48[0.37,0.62]$ & & $\rightarrow$ & & \\
\hline Kim 2018 & 0.9282 & 0.3557 & $3.9 \%$ & $2.53[1.26,5.08]$ & & & - & \\
\hline Lai 2016 & 0.2624 & 0.0282 & $12.1 \%$ & $1.30[1.23,1.37]$ & & &. & \\
\hline Ovesen 2014 & 0.3365 & 0.0661 & $11.4 \%$ & $1.40[1.23,1.59]$ & & & + & \\
\hline Saydah 2005 & 0.5128 & 0.272 & $5.4 \%$ & $1.67[0.98,2.85]$ & & & $\longrightarrow$ & \\
\hline Shindo 2019 & -0.2231 & 0.4675 & $2.6 \%$ & $0.80[0.32,2.00]$ & & & - & \\
\hline Srichumchit 2015 & 0.392 & 0.0741 & $11.2 \%$ & $1.48[1.28,1.71]$ & & & $=$ & \\
\hline Stone 2002 & 0.6931 & 0.0538 & $11.7 \%$ & $2.00[1.80,2.22]$ & & & $*$ & \\
\hline Xiong 2001 & 0.1133 & 0.0233 & $12.1 \%$ & $1.12[1.07,1.17]$ & & & 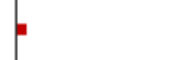 & \\
\hline Total $(95 \%$ Cl) & & & $100.0 \%$ & $1.36[1.15,1.60]$ & & & $\checkmark$ & \\
\hline $\begin{array}{l}\text { Heterogeneity: Tau } \\
\text { Test for overall effect }\end{array}$ & $\begin{array}{l}0.06 ; \mathrm{Chi}^{2}=202.9 \\
Z=3.62\langle P=0.00\end{array}$ & $\begin{array}{l}\text { 14, } d f=1 \\
03)\end{array}$ & $(P<0.00$ & $0001) ;\left.\right|^{2}=95 \%$ & 0.0 & 0.1 No GDM & $i$ & 100 \\
\hline
\end{tabular}

\section{Figure 2. Forest plot of the influence of gestational diabetes mellitus on macrosomia birth}

Interpretation of the results of the metaanalysis process can be seen through the forest plot. Figure 2 shows that there is a statistically significant effect of gestational 
Ratna et al./ Effect of Gestational Diabetes Mellitus on Macrosomia and Sectio Caesarea

diabetes mellitus on the risk of macrosomia birth. Pregnant women with gestational diabetes mellitus have a risk of giving birth to a macrosomic baby 1.36 times compared

\section{b. Funnel Plot}

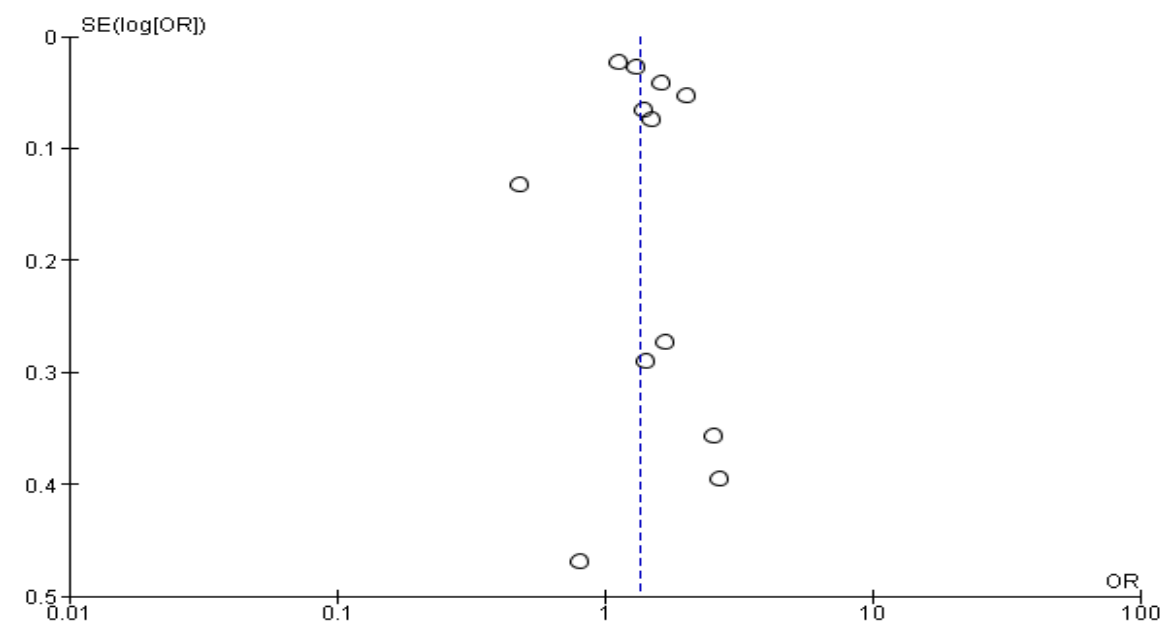

Figure 3. Funnel plot effect of gestational diabetes mellitus on macrosomia birth

The funnel plot in Figure 3 shows the asymmetric distribution of the primary study estimates. The funnel plot indicates that there is a publication bias that tends to to those without gestational diabetes mellitus $(\mathrm{aOR}=1.36 ; 95 \% \mathrm{CI}=1.15$ to 1.60 ; $\mathrm{p}<0.003)$.

\section{Effect of gestational DM on cesarean section delivery}

\section{a. Forest Plot}

overestimate the true effect of gestational diabetes mellitus on the risk of macrosomia births (overestimate).

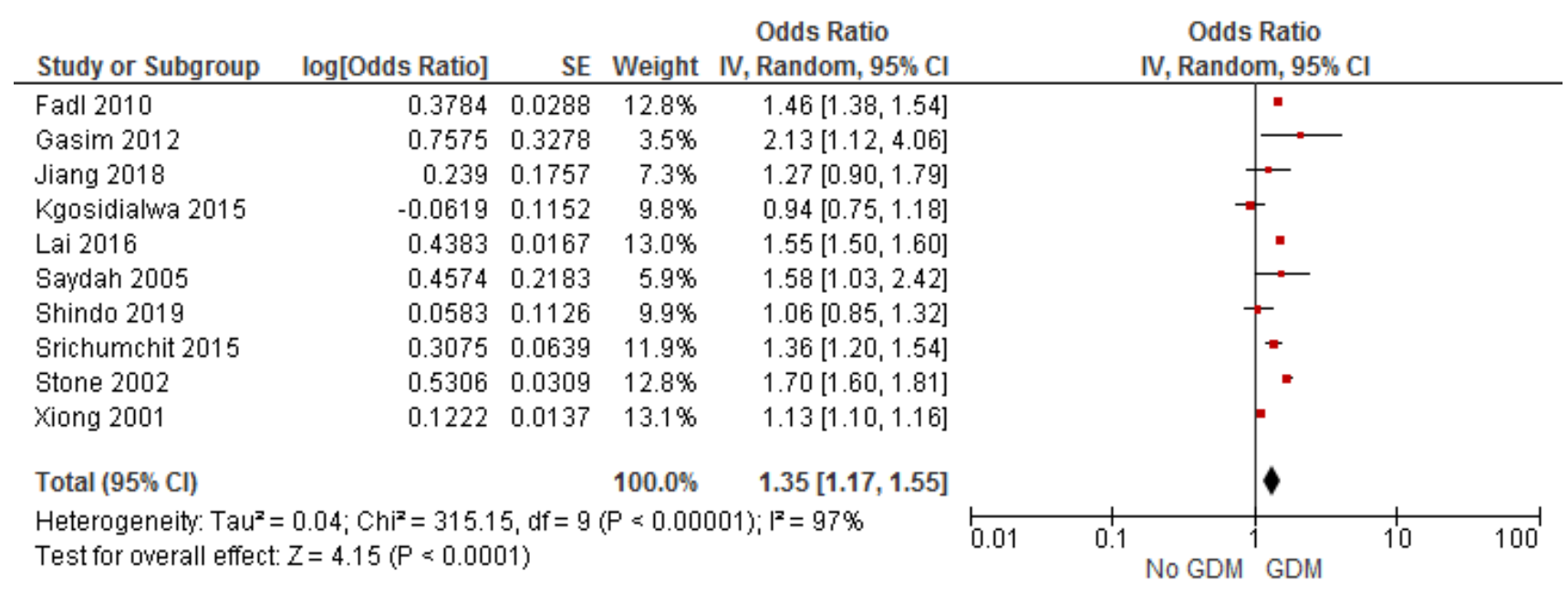

\section{Figure 4. Forest plot of the influence of gestational diabetes mellitus on cesarean delivery}

Figure 4 shows that there is a statistically significant effect of gestational diabetes mellitus on the risk of cesarean delivery. Pregnant women with gestational diabetes mellitus had a risk of cesarean delivery 1.35 times compared to those without gestational diabetes mellitus $(\mathrm{aOR}=1.35$; $95 \% \mathrm{CI}=1.17$ to $1.55 ; \mathrm{p}<0.001)$. 


\section{b. Funnel Plot}

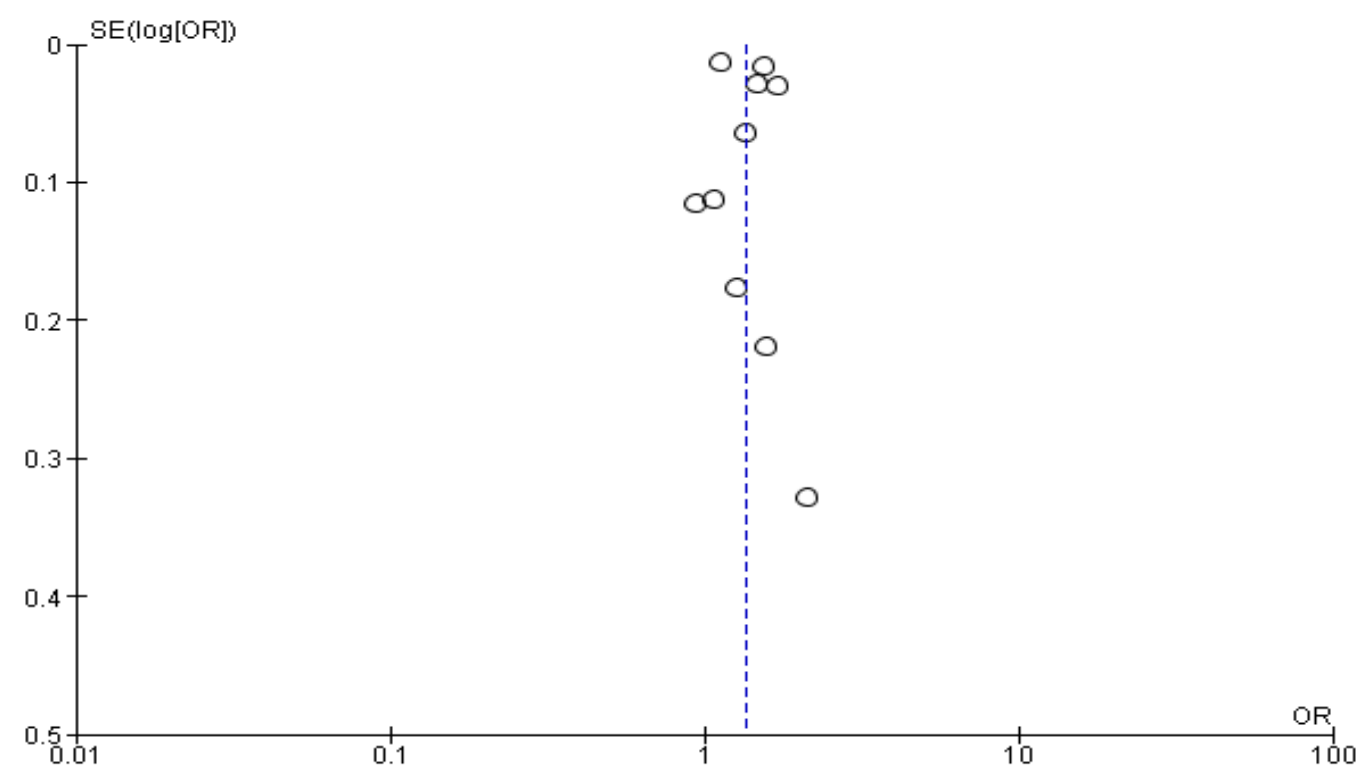

Figure 5. Funnel plot of the influence of gestational diabetes mellitus on cesarean delivery

The funnel plot of Figure 5 shows a symmetrical distribution of the primary study estimates, 5 plots on the right and 5 plots on the left. The funnel plot does not indicate publication bias.

\section{DISCUSSION}

This study is a study with a systematic study and meta-analysis with the theme of the effect of gestational diabetes mellitus. The independent variable was gestational diabetes mellitus. The dependent variables studied were macrosomia birth and caesarean section. The results of the primary study conducted by a systematic review and meta-analysis showed an epidemiological study design with a larger sample, different demographic characteristics in both developed and developing countries, thus providing a basis for concluding that gestational diabetes mellitus affects the birth of macrosomia and sectio casear

Gestational diabetes mellitus (GDM) is caused by -cell destruction and tissue insulin resistance. In most cases, it is present before pregnancy and can be progressive or represent an increased risk of T2DM (type 2 diabetes mellitus) after pregnancy. A number of additional organs and systems contribute to or are affected by GDM including the brain, adipose tissue, liver, muscle and placenta (Plows et al., 2018).

GDM increases the risk of a number of short- and long-term maternal health problems. GDM is associated with antenatal depression as well as the risk of complications of preterm delivery, preeclampsia and in most cases operative delivery. Approximately $60 \%$ of women with a history of GDM develop T2DM later in life. Each subsequent pregnancy also provided a threefold increase in the risk of T2DM in women with a history of GDM. Emerging evidence also shows that the blood vessels of women with previous cases of GDM are permanently altered, thus predisposing to cardiovascular disease (CVD) (Plows et al., 2018) 
In addition, DMG also increases short-term and long-term health risks in infants, such as increased transport of glucose, amino acids, and fatty acids that stimulate the production of endogenous fetal insulin and insulin-like growth factor 1 or insulin-like growth factor 1 (IGF-1). This can lead to fetal overgrowth, often resulting in macrosomia at birth. As noted earlier, fetal insulin overproduction can suppress pancreatic -cell development, contributing to -cell dysfunction and insulin resistance, even before birth. Macrosomia is also a risk factor for shoulder dystocia (a form of obstructed labour). Therefore, babies from GDM pregnancies are usually delivered by cesarean section (Plows et al., 2018).

This study uses previous primary studies that control confounding factors, this can be seen based on the inclusion requirements of the study using multivariate analysis and the statistical results are adjusted odd ratio (aOR). According to Murti (2018), the confounding factor is a mixture of estimates of the relationship between exposure and the disease under study, by other factors related to both disease and exposure. These confounding factors can affect the relationship or effect of exposure on the occurrence of disease that is estimated or estimated by the study is not the same as the relationship or effect that actually occurs in the target population, or the study results are invalid (incorrect).

The results of the study are presented in the form of forest plots and funnel plots. Forest plots can show effect sizes and 95\% confidence intervals or display results from meta-analysis studies (Makowski et al., 2019). The funnel plot shows the effect size and precision of the effect size and makes it possible to evaluate the possibility of publication bias in the form of a symmetrical triangle graphic (Makowski et al., 2019; Li et al., 2020).

\section{Effects of gestational diabetes mellitus on macrosomia}

The results of the forest plot of research articles with a cohort design showed that there was a statistically significant effect of gestational diabetes mellitus on the risk of macrosomia birth. Pregnant women with gestational diabetes mellitus had a risk of giving birth to a macrosomic baby 1.36 times compared to those without gestational diabetes mellitus $(\mathrm{aOR}=1.36$; 95\% $\mathrm{CI}=1.15$ to $1.60 ; \mathrm{p}<0.003)$.

The results of this study are supported by other studies, such as Gasim, (2012), who found that gestational diabetes mellitus had a 2.67 risk of developing macrosomia and the results were statistically significant $(\mathrm{aOR}=2.67 ; 95 \% \mathrm{CI}=1.23$ to $5.78 ; \mathrm{p}=0.019$ ). In some cases, GDM can negatively impact pregnancy and result in adverse perinatal outcomes such as macrosomia, birth trauma, shoulder distortion and higher caesarean section rates.

Another study also conducted by Stone et al., (2002), stated that gestational diabetes mellitus was at risk of 2.00 times of macrosomia birth and the results were statistically significant $(\mathrm{aOR}=2.00 ; 95 \%$ $\mathrm{CI}=1.80$ to $2.22 ; \mathrm{p}<0.001)$. Women with GDM in this study were found to have a higher proportion of obstetric complications including pre-eclampsia, preterm and cesarean delivery, as well as mean birth weight, LGA (Large Gestational Age) and macrosomic infants than the control group.

A similar study on gestational diabetes mellitus and macrosomia births was conducted by Ovesen et al., (2014), which stated that Gestational Diabetes Mellitus had a 1.40 times risk of having a macrosomia birth and was statistically significant $(\mathrm{aOR}=1.40 ; 95 \% \quad \mathrm{CI}=1.23$ to 1.59 ; $\mathrm{p}<0.001)$. According to the Pedersen 
hypothesis, fetal macrosomia in diabetic women is related to transplacental glucose transport that stimulates fetal hyperinsulinemia and thus fetal growth overgrowth.

Srichumchit et al., (2015) in their study stated that gestational diabetes mellitus had a greater risk of macrosomia birth $(\mathrm{aOR}=1.48 ; 95 \% \mathrm{CI}=1.28$ to $1.71 ; \mathrm{p}<$ 0.001). Fetal overgrowth is the most common side effect of GDM and is associated with a higher risk of other complications such as birth injury, cesarean delivery, or stillbirth. In addition, fetal weight is also an indicator of maternal glucose levels. In the present study, the incidence of fetal macrosomia in the GDM group was 20\%, which is similar to previously reported values and much higher than that of the control group. In utero, fetal growth is associated with fetal hyperinsulinemia, maternal hyperglycemia, and insulin resistance, which collectively increase availability of fetoplacental nutrients, especially in late pregnancy.

Kgosidialwa et al., (2015) state that gestational diabetes mellitus has a risk of developing macrosomia births $(\mathrm{aOR}=0.48$; $95 \% \mathrm{CI}=0.37$ to $0.62 ; \mathrm{p}<0.01)$. This is supported by Kim et al., (2018) which states that gestational diabetes mellitus is a significant factor for the occurrence of macrosomia births $(\mathrm{aOR}=2.53$; 95\% $\mathrm{CI}=$ 1.26 to $5.08 ; \mathrm{p}<0.05)$. A recent study showed that overweight and obesity before pregnancy constitute a significant proportion of macrosomic infants.

The results of the study by Fadl et al., (2010) stated that the risk of macrosomia increased significantly among gestational diabetes mellitus compared to those without gestational diabetes mellitus $(\mathrm{aOR}=$ $1.63 ; 95 \% \mathrm{CI}=1.50$ to $1.77 ; \mathrm{p}<0.001)$. Another study was also conducted by Xiong et al., (2001) which stated that gestational diabetes mellitus has a risk of macrosomia birth, because fetal macrosomia is a consequence of fetal hyperinsulinemia caused by increased transfer of glucose and other nutrients from the fetus to the mother. Macrosomia can also cause difficulties during labor as indicated by complications such as shoulder dystocia, birth trauma, need for early or premature delivery and operative delivery $(\mathrm{aOR}=1.12 ; 95 \% \mathrm{CI}=$ 1.07 to $1.17 ; \mathrm{p}<0.05$ )

Lai et al., (2016) found that GDM was associated with a statistically significant increase in macrosomia births $(\mathrm{aOR}=1.30$; $95 \% \mathrm{CI}=1.23$ to $1.37 ; \mathrm{p}<0.001)$. Women who have GDM are at risk of developing recurrent GDM in subsequent pregnancies and type 2 diabetes later in life.

In contrast to the results of Saydah et al., (2005), $(\mathrm{aOR}=1.50 ; 95 \% \mathrm{CI}=0.98$ to 2.86; $\mathrm{p}=0.06)$. This is in line with Jiang et al., $(2018)(\mathrm{aOR}=1.41 ; 95 \% \mathrm{CI}=0.80$ to 2.46; $\mathrm{p}=0.232$ and Shindo et al., (2019) $(\mathrm{aOR}=0.80 ; 95 \% \mathrm{CI}=0.32$ to $1.71 ; \mathrm{p}=$ 0.58). In addition, it could also be due to the fact that the primary cohort study article had a large enough loss to follow-up in the exposed group which could affect the results of the study so that the results were overestimated.

\section{The effect of gestational diabetes mellitus on sectio caesarean}

There are 10 research articles that became the source of meta-analysis of the effect of gestational diabetes mellitus on caesarean section. The results of the forest plot of research articles with a cohort design showed that there was a statistically signifycant effect of gestational diabetes mellitus on the risk of macrosomia birth. Pregnant women with gestational diabetes mellitus had a risk of giving birth to a macrosomic baby 1.35 times compared to those without gestational diabetes mellitus $(\mathrm{aOR}=1.35$; $95 \% \mathrm{CI}=1.17$ to $1.55 ; \mathrm{p}<0.001)$. 
The results of this study are supported by Stone et al., (2002) which aims to study the pattern of the spread of Gestational Diabetes Mellitus or events related to GDM, along with the factors that can influence these events. In this study, it was found that there was a relationship between GDM and caesarean section $(\mathrm{aOR}=1.70$; 95\% $\mathrm{CI}=1.60$ to $1.81 ; \mathrm{p}<0.001)$. GDM women have a higher intervention to undergo induction and cesarean delivery. This is in line with the Xiong et al., (2001) which said that DMG can increase the risk of cesarean section 1.13 times compared to no $\mathrm{DMG}(\mathrm{aOR}=1.13 ; 95 \% \mathrm{CI}=1.10$ to 1.16 ; $\mathrm{p}<0.05$ ). This study supports previous studies that women with GDM have a higher proportion of obstetric complications including pregnancy-induced hypertension, gestational hypertension, preeclampsia, premature rupture of membranes, caesarean section and preterm delivery, as well as macrosomia and preterm delivery.

Fadl et al., (2010) said that the incidence of cesarean section increased in the group of DMG women with a risk of 1.46 times compared to those without DMG $(\mathrm{aOR}=1.46 ; 95 \% \mathrm{CI}=1.38$ to $1.54 ; \mathrm{p}$ $<0.001)$. This is in line with Gasim (2012) which aims to assess maternal and fetal complications with GDM compared to those without GDM, the results obtained were caesarean section rates that were significantly higher than women without GDM $(\mathrm{aOR}=2.13 ; 95 \% \mathrm{CI}=1.12$ to $4.06 ; \mathrm{p}=$ o.0019). The main indications for cesarean section in this study were maternal hypertension, macrosomia, inconclusive fetal heart examination results, failure to thrive and a history of previous cesarean section.

Srichumchit et al., (2015) showed that GDM increased the risk of cesarean section by 1.36 times compared to no DMG (aOR= $1.36 ; 95 \% \mathrm{CI}=1.20$ to $1.54 ; \mathrm{p}<0.001)$. The cesarean delivery rate was much higher in the GDM group than in the control group, this is related to the high incidence of fetal macrosomia in the GDM group. Lai et al., (2016) found that GDM showed a statistically significant association with an increase in caesarean section $(\mathrm{aOR}=1.55 ; 95 \%$ $\mathrm{CI}=1.50$ to $1.60 ; \mathrm{p}<0.001$ ).

There are several studies where there is no significant relationship between GDM and caesarean section, such as Jiang et al., (2019) $(\mathrm{aOR}=1.27 ; 95 \% \mathrm{CI}=0.90$ to 1.79 ; $\mathrm{p}=0.17$ ), which explains the lack of data records. This is in line with Kgosidialwa et al., (2015), $(\mathrm{aOR}=0.94 ; 95 \% \mathrm{CI}=0.75$ to 1.18; $\mathrm{p}=0.55$ ) and Shindo et al., (2010), $(\mathrm{aOR}=1.06 ; 95 \% \mathrm{CI}=0.85$ to $1.32 ; \mathrm{p}=$ 0.58). This is in line with Kgosidialwa et al., (2015), $(\mathrm{aOR}=0.94 ; 95 \% \mathrm{CI}=0.75$ to 1.18 ; $\mathrm{p}=0.55)$ and Shindo et al., (2010), (aOR= 1.06; $95 \% \mathrm{CI}=0.85$ to $1.32 ; \mathrm{p}=0.58)$. In the results of this meta-analysis, there are several important confounding factors to be controlled by researchers such as respondent's age, disease history, diet/diet, physical activity and history of caesarean section.

\section{AUTHOR CONTRIBUTION}

Tantri Yunita Ratna is the main researcher who chooses the topic, conducts a search for data collection in this study. Yulia Lanti Retno Dewi and Bhisma Murti conducted data analysis and review of research documents.

\section{FUNDING AND SPONSORSHIP}

This study is self-funded.

\section{CONFLICT OF INTEREST}

There is no conflict of interest in this study.

\section{ACKNOWLEDGMENT}

The researcher would like to thank all those who have helped in the preparation of this 
article and also thank the database providers PubMed, ScienceDirect, and Google Scholar.

\section{REFERENCES}

Baz B, Riveline JP, Gautier JF (2016). Gestational diabetes mellitus: Definition, aetiological and clinical aspects. European Journal of Endocrinology, 174(2): R43-R51. doi: 10.1530/EJE$15-0378$.

Biratu AK, Wakgari N, Jikamo B (2018). Magnitude of fetal macrosomia and its associated factors at public health institutions of Hawassa city, southern Ethiopia. BMC Research Notes. BioMed Central. 11(1): 1-6. https://doi.org/10.1186/s13104-018-4005-2.

Fadl HE, Ostund IKM, Magnuso AFK, Hanson USB (2010). Maternal and neonatal outcomes and time trends of gestational diabetes mellitus in Sweden from 1991 to 2003. Diabetic Medicine. 27(4): 436-441. https://doi.org/10.1111/j.1464-5491.2010.02978.x.

Gasim T (2012). Gestational diabetes mellitus: Maternal and perinatal outcomes in 220 saudi women. Oman Med J. 27(2): 140-144. https://doi.org/10.5001/omj.2012.29.

Glastras S, Fulcher G (2012). Guidelines for the management of gestational diabetes in pregnancy. Clin Prac. 9(2): 161-170. https://doi.org/10.2217/cpr.12.9.

Groof Z, Garashi G, Husain H, Owayed S, Albader S, Hawra, Mouhsen, Mohammad A, Ziyab AH (2019). Prevalence, risk factors, and fetomaternal outcomes of gestational diabetes mellitus in Kuwait: a cross-sectional study. J Diabetes Res. 2019: 9136250. https://doi.org/10.1155/2019/9136250.

Hossein-nezhad A, Maghboolo Z, Vassigh AR, Larijani (2007). Prevalence of gestational diabetes mellitus. Obstet Gynecol. 46(3): 236-241. https://doi.org/10.1016/s1028-4559(08)60026-1.

Jiang T, Zhao L, Lin Y, Zhou D, Wang L, Sun G, Xiao M (2019). Effects of gestational diabetes mellitus on time to delivery and pregnancy outcomes in full-term pregnancies with dinoprostone labor induction. Clin and Exp Hypertens. 41(1): 44-48. https://doi.org/10.1080/10641963.2018.14 41859.

Kaur G, Sharma S (2011). Effect of passive straight leg raise sciatic nerve mobilization on low back pain of neurogenic origin. Indian $\mathrm{J}$ Physiother Occup Ther. 5(3): 179-184. https://doi.org/10.1016/j.ajog.2010.11.039.Is.

Kgosidialwa O, Egan A M, Carmody L, Kirwan B, Gunning P, Dunne FP (2015). Treatment with diet and exercise for women with gestational diabetes mellitus diagnosed using IADPSG criteria. J Clin Endocrinol Metab. 100(12): 4629-4636. https://doi.org/10.1210/jc.2015-3259.

Kim $\mathrm{MH}$, Kwak SH, Kim SH, Hong JS, Chung HR, Choi SH, Kim MY, Jang HC (2019). Pregnancy outcomes of women additionally diagnosed as gestational diabetes by the International Association of the Diabetes and Pregnancy Study groups criteria. Diabetes Metab J. 43(6): 766-775. https://doi.org/10.4093/dmj.2018.0192.

Lai FY, Johnson JA, Dover D, Kaul P (2016). Outcomes of singleton and twin pregnancies complicated by preexisting diabetes and gestational diabetes: A population-based study in Alberta, Canada, 2005-11. J Diabetes. 8(1): 45-55. https://doi.org/10.1111/1753-0407.12255.

Li G (2020). Multiple uses of forest plots in 
presenting analysis results in health research. J Clin Epidemiol. 117: 8998. https://doi.org/10.1016/j.jclinepi.2019.09.021.

Makowski D, Piraux F, Brun F (2019). From experimental network to metaanalysis methods and applications with $\mathrm{R}$ for agronomic and environmental sciences. France: Springer Nature B.V.

Muche AA, Olayemi OO, Gete YK (2020). Gestational diabetes mellitus increased the risk of adverse neonatal outcomes: A prospective cohort study in Northwest Ethiopia. Midwifery. 87: 102713. https://doi.org/10.1016/j.midw.2020.102713.

Ovesen PG, Jensen DM, Damm P, Rasmussen S, Kesmodel US (2015). Maternal and neonatal outcomes in pregnancies complicated by gestational diabetes. A nation-wide study. J Matern Fetal Neonatal Med. 28(14): 17201724. https://doi.org/10.3109/14767058.2014.966677.

Plows JF, Stanley JL, Baker PN, Reynolds CM, Vickers MH (2018). The pathophysiology of gestational diabetes mellitus. Int J Mol Sci. 19(11): 3342. https://dx.doi.org/10.3390\%2Fijms1 9113342.

Reinders P, Zoellner Y, Schneider U (2020). Real-world evaluation of adverse pregnancy outcomes in women with gestational diabetes mellitus in the German health care system. Prim Care Diabetes. 14(6): 633-638. https://doi.org/10.1016/j.pcd.2020.0 4.009.

Murti B. (2018) Prinsip Dan Metode Riset Epidemiologi. $5^{\text {th }}$ edition. Karanganyar: Program Studi Ilmu Kesehatan Masyarakat.

Shindo R, Aoki S, Kasai J, Saigusa Y, Nakanishi S, Miyagi E (2010). Dampak pengenalan kriteria Asosiasi Internasional Diabetes dan Kelompok Studi Kehamilan (IADPSG) pada hasil kehamilan di Jepang.

Sivak HD, Pérez A, Diaz-Alonso J (2001). Screening effects in relativistic models of dense matter at finite temperature. Progress of Theoretical Physics, 105(6): 961-978. https://doi.org/10.1143/PTP.105.961.

Srichumchit S, Luewan S, Tongsong T (2015). Outcomes of pregnancy with gestational diabetes mellitus. Int $\mathrm{J}$ Gynaecol Obstet. 131(3): 251-4. https://doi.org/10.1016/j.ijgo.2015.0 5.033 .

Stone CA, McLachian KA, Halliday JL, Wein P, Tippett C (2002). Gestational diabetes in Victoria in 1996: Incidence, risk factors and outcomes. Med J Australia. 177(9): 486-491. https://doi.org/10.5694/j.1326-5377.2002.tbo4916.x.

Su WJ, Chen YL, Huang P Y, Shi XL, Yan FF, Chen Z, Yan B, Song HQ, Lin MZ, Li XJ (2019). Effects of prepregnancy body mass index, weight gain, and gestational diabetes mellitus on pregnancy outcomes: A population-based study in Xiamen, China, 2011-2018. Ann Nutr Metab. 75(1): 31-38. doi: 10.1159/000501710.

Wang J, Chen K, Jin X, Li X, An P, Yang N, Chen Y, Fang Y, Mu Y (2019). Prognostic factors for cesarean section outcome of pregnant women with gestational diabetes mellitus: A systematic review and meta-analysis. Diabetes Metab Syndr Obes. 12: 913-929. https://dx.doi.org/10.2147\%2FDMSO .S188293.

Xiong X, Saunders LD, Wang FL, Demianczuk NN (2001). Gestational diabetes mellitus: Prevalence, risk factors, maternal and infant outcomes. Int $\mathrm{J}$ 
Ratna et al./ Effect of Gestational Diabetes Mellitus on Macrosomia and Sectio Caesarea

Gynecol Obstet. 75(3): 221-228. https://doi.org/10.1016/Soo20-7292(01)00496-9.

Z Zhou, G Cen, D Fan, J Rao, P Li, S Wu, D Lin, et al. (2020). Size and shape of associations of OGTT as well as mediating effects on adverse preg- nancy outcomes among women with gestational diabetes mellitus: Population-based study from Southern Han Chinese. Frontiers in Endocrinol, 11: 135. https://doi.org/10.3389/fendo.2020.00135. 